\title{
Pengambilan Keputusan Strategi Pemasaran Terbaik pada PT. Astra International TBK. UD Truck SO Cabang Semarang
}

\author{
Sania Bunga Pradani Hernanti, Dwi Eko Waluyo, Dwi Nurul Izzhati \\ Program Studi Teknik Industri, Fakultas Teknik, Universitas Dian Nuswantoro Semarang \\ Jl. Nakula 1 No.5-11, Semarang - Jawa Tengah, 50131 \\ Email: $\underline{512201300632 @ m h s . d i n u s . a c . i d}$
}

\begin{abstract}
The sale of UD Truck Quester unit at PT Astra International UD Truck SO Semarang branch does not show any improvement in 2015. This condition even tends to stagnate. Not achieving the target that has been set is an indication that the marketing strategy that is used today has not given optimal results. Therefore, the need for a new marketing strategy that can drive sales in PT Astra International UD Truck SO Semarang branch. Nevertheless, of course the marketing strategy developed will be very diverse and needs to be chosen well so as to give the best results. For this reason we use the Analytical Network Process (ANP) method and also TOPSIS (Technique for Order Preference by Similarity to Ideal Solution) to select the best marketing strategy in choosing the best marketing strategy. The result of this research got the conclusion that best strategy chosen for PT. Astra International UD Truck SO Semarang Branch is a segmentation based on the ideal solution of negative and positive.
\end{abstract}

Keywords :ANP, Marketing Strategy, Porter Strategy, TOPSIS

\begin{abstract}
Abstrak
Penjualan unit UD Truck Quester di PT Astra International UD Truck SO cabang Semarang tidak menunjukkan adanya peningkatan pada tahun 2015. Kondisi ini bahkan cenderung stagnan. Tidak tercapainya target yang telah ditetapkan merupakan suatu indikasi bahwa strategi pemasaran yang digunakan saat ini belum memberikan hasil yang optimal. Oleh karena itu, perlu adanya suatu strategi pemasaran baru yang dapat mendorong penjualan di PT Astra International UD Truck SO cabang Semarang. Namun demikian, tentu saja strategi pemasaran yang dikembangkan akan sangat beragam dan perlu dipilih dengan baik sehingga dapat memberikan hasil yang terbaik. Untuk itulah digunakan metode Analytical Network Process (ANP) dan juga TOPSIS (Technique for Order Preference by Similarity to Ideal Solution) untuk memilih srategi pemasaran terbaik dalam pemilihan strategi pemasaran terbaik ini. Adapun hasil dari penelitian ini didapatkan kesimpulan bahwa strategi terbaik yang terpilih bagi PT. Astra International UD Truck SO Cabang Semarang adalah segmentasi berdasarkan solusi ideal negative dan positif.
\end{abstract}

Kata kunci: ANP, Strategi Pemasaran, Strategi Porter, TOPSIS 1. Pendahuluan

Membangun keunggulan kompetitif dengan menghasilkan nilai bagi konsumen telah menjadi sorotan utama dalam strategic marketing. Suatu perusahaan akan mencapai keunggulan kompetitif ketika perusahaan tersebut menawarkan nilai yang berbeda dari pesaingnya. Christensen mendefinisikan keunggulan kompetitif sebagai semua nilai yang dibuat oleh perusahaan yang dapat memotivasi konsumen untuk membeli produk atau layanan perusahaan tersebut dibandingkan dengan kompetitornya serta menyulitkan kompetitor untuk meniru nilai tersebut [1]. 
PT. Astra International Tbk. UD Truck SO Cabang Semarang merupakan salah satu perusahaan di Indonesia yang bergerak di bidang otomotif, terus meningkatkan kualitas dan kuantitas pelayanan terhadap kepuasan pelanggan. Kegiatan pemasaran yang dilakukan PT. Astra International Tbk. UD Truck SO Cabang Semarang merupakan sarana bagi perusahaan untuk menginformasikan produk UD Truck Quester sehingga produknya lebih dikenal oleh masyarakat dan tertanam di benak masyarakat Semarang dan sekitarnya, kemudian akan tertarik dan terbujuk untuk melakukan pembelian yang pada akhirnya akan meningkatkan volume penjualan. Dalam memasarkan produk-produknya selama ini, PT. Astra International Tbk. UD Truck SO Cabang Semarang menggunakan strategi pemasaran Maintanance Strategy sebagai pedoman dalam melakukan kegiatan pemasaran yaitu dengan melakukan membangun hubungan terhadap current consumen sehingga tujuan yang ingin dicapai yaitu terjadi pembelian berulang dari konsumen tersebut. Strategi ini diambil dikarenakan keadaan pasar dimana trend volume yang akan datang tidak dapat diprediksi, dan PT. Astra International Tbk. UD Truck SO Cabang Semarang sebagai perusahaan otomotif dengan market share yang cukup memimpin dan selalu menggunakan stategi yang sama dengan yang digunakan saat produk-produknya mencapai tahap mature.

Penjualan perusahaan untuk setiap bulannya dari periode tahun 2014 sampai tahun 2016, menunjukkan bahwa penjualan tiap tahun selama periode penjualan tahun 2014-2016 belum mencapai target tahunan yang sudah ditetapkan yaitu sebanyak 180 unit per tahun atau 15 unit per bulan. Jika dilihat dari penjualan yang memenuhi target bulanan perjualan yang memenuhi target hanya ada 2 kali yaitu pada tahun 2015 dengan penjualan lebih dari 15unit terjual yaitu penjualan pada bulan Oktober dan November, sedangkan penjualan bulanan lainnya tidak ada yang memenuhi target penjualan bulanan dan tahunan.

Berdasarkan dari analisa kepuasan konsumen yang diakukan oleh PT. Astra International UD Truck SO Cabang Semarang, sebagian besar konsumen masih merasa kegiatan promosi yang dilakukan PT. Astra International UD Truck SO Cabang Semarang masih sagat kurang dibandingkan dengan pesaingnya, walaupun konsumen menganggap produk UD Truck mempunyai kualitas dan kenyamanan yang tidak kalah dengan pesaingnya, beberapa konsumen merasa pelayanan yang diberikan dari dealer masih kurang memuaskan dari segi kecepatan merespon keluhan konsumen dan menanggapi permintaan konsumen. Dari hasil wawancara yang penulis lakukan kepada pihak perusahaan salah satu penyebab tidak tercapainya target penjualan dikarenakan terjadinya penurunan kinerja karyawan yang menyebabkan performa penjualan tidak bisa optimal. Kondisi ini menunjukkan bahwa penggunaan strategi pemasaran yang saat ini digunakan oleh PT. Astra International Tbk. UD Truck SO Cabang Semarang belum dapat memberikan hasil yang optimal. Hal ini tentunya menjadi perhatian yang sangat khusus bagi divisi penjualan UD Truck pada PT Astra Internasional UD Truck SO Cabang Semarang. Tujuan Penelitian ini adalah mengidentifkasi hubungan antar kriteria dan subkriteria yang akan digunakan, menentukan bobot kriteria dan subkriteria sumber daya pemasaran, menentukan strategi pemasaran terbaik serta memberikan rekomendasi strategi pemasaran berdasarkan strategi pemasaran yang terpilih. Mohaghar, dkk menjabarkan bahwa terdapat enam kriteria sumber daya pemasaran yang mempengaruhi pemilihan strategi pemasaran [2]. Enam kriteria ini merupakan pengembangan dari penelitian Holley [3] yaitu Managerial Capabilities, Customer Linking Capabilities, Market Innovation Capabilities, Human Resource Asset, dan Reputational Asset.

\section{Metode Penelitian}

Metodologi penelitian ini digunakan sebagai acuan dalam melakukan penelitian sehingga proses penelitian yang dilakukan dapat berjalan dengan sistematis. Dengan adanya metodologi ini, maka siklus pemecahan masalah dapat dilaksanakan secara terstruktur.

\subsection{Variabel}

Variabel yang digunakan pada penelitian ini berdasarkan penelitian Mohaghar [2]. Terdapat 6 kriteria sumber daya pemasaran yaitu managerial capabilities (MC), customer linking capabilities (CLC), market innovation capabilities (MIC), human resource assets (HRA), capabilities in product distribution (CIPD), dan reputational assets (RA). Masing-masing kriteria ini memiliki subkriteria sumber daya pemasaran. Subkriteria untuk masing-masing kriteria dapat dilihat pada Tabel 1. 
Tabel 1 Kriteria Dan Subkriteria Sumber Daya Pemasaran

\begin{tabular}{|c|c|}
\hline Kriteria & Subkriteria \\
\hline \multirow{3}{*}{$\begin{array}{l}\text { Managerial } \\
\text { Capabilities }\end{array}$} & Kondisi Finansial \\
\hline & Manajemen SDM yang Efektif \\
\hline & Manajemen Operasi yang Baik \\
\hline \multirow{5}{*}{$\begin{array}{l}\text { Customer Linking } \\
\text { Capabilities (CLC) }\end{array}$} & Tingkat Layanan Konsumen \\
\hline & Hubungan Dengan Key Target Konsumen \\
\hline & Memahami Kebutuhan Konsumen \\
\hline & Membangun Hubungan Dengan Konsumen \\
\hline & Membina Hubungan Dengan Konsumen \\
\hline \multirow{2}{*}{$\begin{array}{l}\text { Market Innovation } \\
\text { Capabilities (MIC) }\end{array}$} & kemampuan Meluncurkan Produk Baru \\
\hline & Proses Pengembangan Produk Yang Efektif \\
\hline \multirow{2}{*}{$\begin{array}{l}\text { Human Resource } \\
\text { Asset (HRA) }\end{array}$} & Tingkat Kepuasan Kinerja Karyawan \\
\hline & Tingkat Retensi Karyawan \\
\hline \multirow{4}{*}{$\begin{array}{l}\text { Capabilities in Product } \\
\text { Distribution( CPD ) }\end{array}$} & Hubungan yang Kuat Dengan Distributor \\
\hline & Mempertahkan Distributor Terbaik \\
\hline & Memberikan Value Terhadap Distributor \\
\hline & Tingkat Dukungan yang Baik Terhadap Distributor \\
\hline \multirow{2}{*}{$\begin{array}{l}\text { Repuational Assets } \\
(R A)\end{array}$} & Brand atau Reputasi \\
\hline & Kredibilitas \\
\hline
\end{tabular}

\subsection{Kuesioner}

Pada penelitian ini terdapat 3 kuesioner yang digunakan, dimana ketiga kuesioner ini harus dilakukan secara berurutan. Kuesioner yang pertama disebarkan adalah kuesioner hubungan antar kriteria. Kuesioner ini bertujuan untuk mengetahui hubungan ketergantungan antar subkriteria sebagai acuan dasar untuk membuat model ANP. Kuesioner yang kedua adalah kuesioner perbandingan berpasangan. Kuesioner ini dibuat berdasarkan hubungan ketergantungan yang didapatkan dari kuesioner pertama. Kuesioner yang ketiga adalah kuesioner judgment metode TOPSIS. Kuesioner ini berfungsi untuk mengetahui kesesuaian alternatif strategi yang ada terhadap sumber daya pemasaran yang dimiliki oleh perusahaan saat ini.

\subsection{Responden}

Responden yang dilibatkan pada penelitian ini adalah Kepala Cabang, Sales Manager, Sales Engineer. Responden ini dipilih karena dianggap menguasai dan memahami pemasaran di PT. Astra International UD Truck SO Cabang Semarang.

a. Membuat model ANP berdasarkan hubungan yang telah diidentifikasi pada tahapan sebelumnya.

b. Membuat matriks perbandingan

c. Menentukan bobot kepentingan tiap subkriteria. Dari tahapan ini, akan didapatkan bobot kepentingan dari hasil normalisasi yang nantinya akan menjadi input untuk penentuan peringkat dengan metode TOPSIS.

d. Penentuan prioritas alternatif strategi dengan metode TOPSIS.

\section{Hasil dan Analisis}

\subsection{Penentuan dan Analisis Hubungan Keterkaitan Antar Sub Kriteria}

Pada tahapan ini dilakukan penentuan hubungan saling ketergantungan antar kriteria dalam satu kelompok (inner dependence) atau antar kelompok (outer dependence). Penentuan hubungan saling ketergantungan tersebut akan dilakukan dengan pembuatan 
kuesioner yang didasarkan pada penelitian yang dilakukan oleh Olivia [4]. Hasil dari hubungan ketergantungan subkriteria dapat dilihat pada Tabel. 2. Jumlah responden (N) adalah tiga orang. Jika dalah suatu blok (baris i - kolom j), jumlah responden yang memilih (Vij) leboh dari atau sama dengan $(\mathrm{N} / 2 \geq 1,5)$, maka terdapat hubungan keterkaitan antar kriteria tersebut. Dari hubungan ini, nantinya akan menjadi dasar dalam pembuatan model ANP dengan menggunakan software super decision.

Pada ANP terdapat dua jenis hubungan ketergantungan, yaitu inner dependence dan outer dependence.

a. Inner dependence

Inner dependence adalah hubungan antar elemen dalam satu cluster yang sama, sehingga cluster ini akan terhubung dengan dirinya sendiri sehingga akan membentuk hubungan loop. Pada penelitian ini terdapat beberapa inner dependence, yaitu ketika terdapat hubungan pengaruh antar subkriteria di dalam satu kriteria yang sama. Sebagai contoh, subkriteria manajemen operasi (MO) dipengaruhi oleh subkriteria kondisi finansial (KF) dan subkriteria manajemen sumber daya manusia (MS). Subkriteria manajemen operasi, kondisi finansial, dan sumber daya manusia merupakan subkriteria dari satu kriteria yang sama yaitu kriteria Managerial Capabilities (MC) sehingga dapat disimpulkan bahwa kriteria Managerial Capabilites memiliki inner dependence. Kemudian, kondisi finansial merupakan inner dependence dari subkriteria kondisi finansial dan subkriteia manajemen operasi. Walaupun hanya terdapat hubungan dengan salah satu subkriteria dalam satu kriteria yang sama, maka kriteria tersebut akan tetap dianggap memiliki inner dependence dan membentuk loop untuk cluster kriteria tersebut

b. Outer Dependence

Outer dependence adalah hubungan antar elemen dalam suatu cluster yang berbeda, sehingga cluster yang satu akan terhubungan satu cluster yang lain. Pada penelitian ini terdapat outer dependence, yaitu ketika terdapat hubungan pengaruh antar subkriteria di dalam satu kriteria yang sama. Sebagai contoh, subkritreria meluncurkan produk baru (MP) mempengaruhi subkriteria manajemen sumber daya manusia (MS) dengan nilai Q sebesar 3. Subkriteria meluncurkan produk baru merupakan subkriteria dari kriteria Market Innovation Capabilities (MIC) dan subkriteria manajemen sumber daya manusia merupakan subkriteria dari kriteria Managerial Capabilties (MC). Karena kedua subkriteria merupakan subkriteria dari kriteria yang berbeda, maka disimpulkan bahwa terdapat outer dependece atau hubungan antara kriteria Market Innovation Capabilities (MIC) dengan kriteria Managerial Capabilties (MC) dimana kriteria Market Innovation Capabilities (MIC) mempengaruhi kriteria Managerial Capabilties (MC). Selain itu, subkriteria meluncurkan produk baru (MP) dipengaruhi oleh subkriteria kondisi finansial (KF). Dikarenakan subkriteria meluncurkan produk baru merupakan subkriteria dari kriteria Market Innovation Capabilities (MIC) dan subkriteria kondisi finansial merupakan subkrieria dari kriteria Managerial Capabilties (MC) sehingga terdapat outer dependence pada kedua kriteria ini dimana kriteria Managerial Capabilties (MC) mempengaruhi kriteria Market Innovation Capabilties. Kedua kriteria ini memiliki hubungan saling mempengaruhi, sehingga terdapat feedback untuk kedua kriteria ini.

Dari model ANP tersebut, dapat dilihat hubungan antar kriteria (Tabel 2), yaitu saling mempengaruhi, salah satu kriteria mempengaruhi atau dipengaruhi oleh kriteria lain, atau terdapat inner dependence sehingga terdapatnya loop. Managerial capabilities memiliki hubungan saling mempengaruhi dengan Customer Linking Capabilities, Market Innovation Capabilities, dan Reputational Asset. Berarti, dalam kemampuan managerial perusahaan dalam pelaksanaa strategi pemasaran memiliki hubungan saling mempengaruhi dengan kemampuan perusahaan untuk meingidentifikasi kemamuan dan kebutuhan konsumen serta aset reputasi dari PT. Astra International UD Truck SO Cabang Semarang. Kluster alternatif memiliki hubungan saling mempengaruhi dengan keseluruhan subkriteria karena dalam menerapkan alternatif strategi pemasaran, sumber daya pemasaran perusahaan akan berpengaruh dan begitu juga sebaliknya. 
Tabel 2 Rekapitulasi Kuesioner Hubungan Antar Kriteria

\begin{tabular}{|c|c|c|c|c|c|c|c|c|c|c|c|c|c|c|c|c|c|c|c|c|}
\hline \multirow{2}{*}{\multicolumn{3}{|c|}{ KRITERIA }} & \multicolumn{18}{|c|}{ YANG DIPENGARUHI } \\
\hline & & & \multicolumn{3}{|c|}{ MC } & \multicolumn{5}{|c|}{ CIC } & \multicolumn{2}{|c|}{ Mic } & \multicolumn{2}{|c|}{ HRA } & \multicolumn{4}{|c|}{$\mathrm{CPO}$} & \multicolumn{2}{|c|}{ RA } \\
\hline & & $\begin{array}{c}\text { SUB } \\
\text { KRITERIA }\end{array}$ & KF & MS & MO & UK & HK & MK & $\mathrm{BH}$ & BK & MP & $P P$ & $\mathbf{x K}$ & RK & HD & MD & MV & To & AR & KD \\
\hline \multirow{18}{*}{ 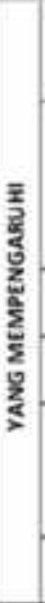 } & \multirow{3}{*}{ MC } & KF & & 2. & 3 & & 1 & 1 & 2 & & 3 & 2 & & 1 & & & & & 3 & 1 \\
\hline & & MS & 2 & & 2. & 3 & 2 & 2 & 2 & 3 & 2 & 2 & 2 & 1 & 3 & & & & 2 & 3 \\
\hline & & MO & 1 & 2 & & 3 & 3 & 3 & 3 & 1 & 1 & 2 & 2 & 1 & & & 2 & 3 & 3 & 2 \\
\hline & \multirow{5}{*}{$\mathrm{CIC}$} & LK & & 1 & 2 & & 3 & 3 & 3 & 3 & 1 & 1 & & 1 & 3 & 2 & & & 1. & 2 \\
\hline & & HK & 1 & 2 & 2. & 2 & & & 3 & 3 & 1 & 1 & 2 & & & & & & 2 & 1 \\
\hline & & MK & 2 & 1 & 2 & 2 & 3 & & 3 & 3 & 2 & 2 & & 1 & & & & & 3 & 3 \\
\hline & & $\mathrm{BH}$ & & & 1. & 2 & 2 & 2 & & 2. & 1 & & 1 & 2 & & & & & 2 & 2 \\
\hline & & $B X$ & 1 & 1 & 3 & 3 & 3 & 3 & 3 & - & 1 & 1 & 3 & 3. & 1 & 1 & 1 & 1 & 3 & 2 \\
\hline & \multirow{2}{*}{ MIC } & $M P$ & 2 & 1 & 2 & 1 & & 3 & 1 & 2 & & 2 & & & 3 & 3 & 3 & 2 & 2 & 2 \\
\hline & & $p p$ & 3 & 2 & 1 & 1 & 2 & 2 & 1 & 1 & 3 & L & & 1 & 1 & 2 & 2 & 1 & 2 & 2 \\
\hline & \multirow{2}{*}{ HRA } & $10 \mathrm{X}$ & 2 & 2 & 3 & 1 & 1 & 2 & 1 & 1 & 1 & 2 & & 2 & & & & & 2 & 2 \\
\hline & & PX & 2 & 2 & & & 2 & & 2 & 2 & & & 1 & & & & & & 1 & 2 \\
\hline & \multirow{4}{*}{ CPD } & HO & & & & 3 & & & & & 3 & 2 & & & & 2 & 2 & 2 & 2 & 2 \\
\hline & & $M D$ & & & & 2 & 1 & & & & 3 & 3 & & 1 & 3 & & 3 & 1 & 2 & 1 \\
\hline & & MV & & & & 1 & 2 & & & & 2 & 2 & & 1 & 3 & 3 & & 3 & 1 & 2 \\
\hline & & To & & 1 & & 1 & 1 & & & & 1 & & & 1 & 2 & 3 & & - & 2 & 1 \\
\hline & \multirow{2}{*}{$R A$} & $B R$ & 1 & 3 & 3 & 3 & 2 & 2 & 2 & 3 & 3 & 2 & 1 & 1 & 2 & 3 & 2 & 1 & & 2 \\
\hline & & KD & 1 & 2 & 2 & 2 & 3 & 2 & 2 & 2 & 2 & 2 & 2 & 2 & 2 & 3 & 3 & 3 & 3 & \\
\hline
\end{tabular}

\subsection{Penentuan dan Analisis Bobot Kepentingan Subkriteria}

Dari model ANP yang sudah ditentukan hubungan antar subkriteria selanjutnya model ANP ini akan digunakan untuk melakukan perbandingan berpasangan berdasarkan kuesioner yang telah disebarkan kepada responden yang telah ditentukan. Kuesioner ini dibuat untuk mengetahui hubungan ketergantungan antar subkriteria dalam satu kriteria yang sama (inner dependence) atau dalam kriteria yang berbeda (outer dependence). Kuesioner ini dibagikan kepada 5 responden sebelumnya. Dengan memasukkan penilaian ahli, melalui perbandingan berpasangan dengan tingkat kepentingan 1-9 seperti pada Tabel 3 ke dalam model tersebut, maka akan diperoleh hasil berupa bobot masing-masing subkriteria.

\begin{tabular}{|c|l|}
\hline Tingkat & Definisi \\
\hline 1 & Kriteria/alternatif yang satu sama penting dengan kriteria/alternatif lainnya \\
\hline 3 & Kriteria yang satu sedikit lebih penting dari kriteria lainnya \\
\hline 5 & Kriteria yang satu jelas lebih penting dari kriteria lainnya \\
\hline 7 & Kriteria yang satu sangat jelas lebih penting dari kriteria lainnya \\
\hline 9 & Kriteria yang mutlak lebih penting dari kriteria lainnya \\
\hline $2,4,6,8$ & Apabila ragu-ragu antara dua nilai yang berdekatan \\
\hline
\end{tabular}

Model ANP yang digunakan pada penelitian ini dapat dilihat pada Gambar 1. Dari perbandingan berpasangan tersebut, akan didapatkan bobot kepentingan untuk masing-masing subkriteria. Setelah perbandingan berpasangan antar subkriteria dan kriteria dilakukan, maka akan didapatkan matriks kelompok (cluster matrix). Matriks kelompok yang merupakan output dari software super decision. Matriks kelompok menggambarkan seberapa besar pengaruh antar cluster. Terhadap alternatif, kriteria yang paling mempengaruhi adalah kriteria

Setelah itu akan didapatkan limiting dan normalized by cluster dari masing-masing subkriteria. Nilai normalisasi untuk cluster didapatkan dari menormalisasikan nilai subkriteria dalam satu kluster sehingga prioritas dari faktor-faktor tersebut akan berjumlah satu. Nilai normalisasi untuk keseluruhan elemen didapatkan dari menormalisasikan nilai subkriteria secara keseluruhan, sehingga total nilai prioritas untuk keselutuhan subkriteria adalah satu. Normalized untuk keseluruhan elemen adalah nilai limiting yang dinormalkan namun tidak mengikutsertakan kelompok alternatives. Hal ini bertujuan karena nilai normalized untuk keseluruhan elemen merupakan input untuk menentukan prioritas dengan metode TOPSIS 


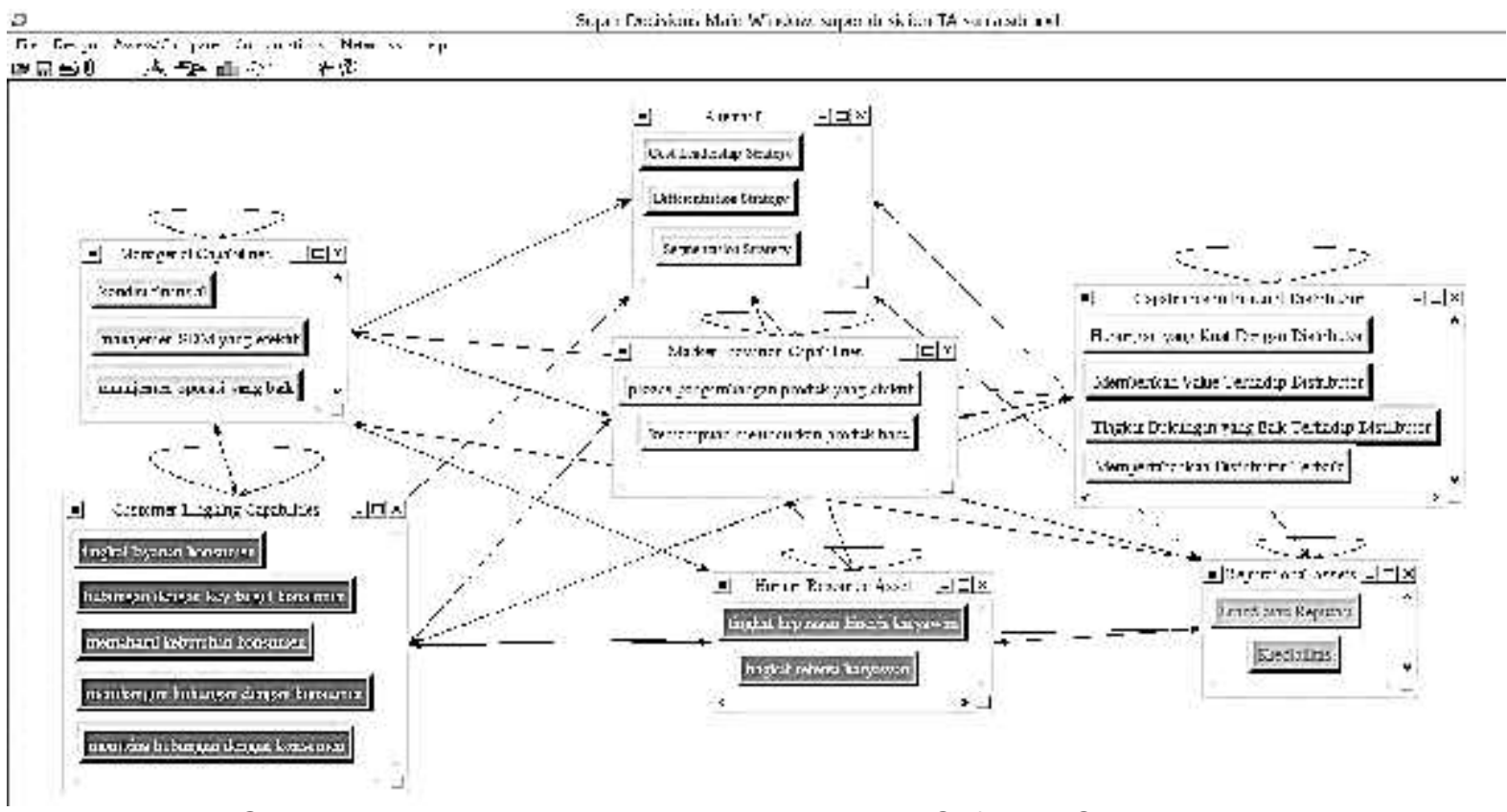

Gambar 1 Model Jaringan ANP Menggunakan Software Super Decisions

Hasil rata-rata rekapitulasi output bobot kepentingan untuk masing-masing subkriteria dapat dilihat pada Tabel 4.

Tabel 4 Bobot Untuk Kriteria dan Subkriteria

\begin{tabular}{|c|c|c|}
\hline & KRITERIA & BOBOT \\
\hline \multicolumn{2}{|r|}{ MANAGERIAL CAPABILITIES } & 0.11834 \\
\hline KF & Kondisi Finansial & 0.09750 \\
\hline MS & Manajemen SDM yang Efektif & 0.51456 \\
\hline \multirow[t]{2}{*}{$\mathrm{MO}$} & Manajemen Operasi yang Baik & 0.38795 \\
\hline & CUSTOMER LINKING CAPABILITIES & 0.15546 \\
\hline LK & Tingkat Layanan Konsumen & 0.06338 \\
\hline $\mathrm{HK}$ & Hubungan dengan Key Target Customer & 0.10612 \\
\hline MK & Memahami Kebutuhan Konsumen & 0.23675 \\
\hline $\mathrm{BH}$ & Membangun Hubungan dengan Konsumen & 0.27683 \\
\hline \multirow[t]{2}{*}{ BK } & Membina Hubungan dengan Konsumen & 0.31692 \\
\hline & MARKET INNOVATION CAPABILITIES & 0.08546 \\
\hline MP & Kemampuan Meluncurkan Produk Baru & 0.16667 \\
\hline $\mathrm{PP}$ & Proses Pengembangan Produk yang Efektif & 0.83333 \\
\hline \multicolumn{2}{|r|}{ HUMAN RESOURCE ASSET } & 0.20228 \\
\hline KK & Tingkat Kepuasan Kerja Karyawan & 0.12500 \\
\hline RK & Tingkat Retensi Karyawan & 0.87500 \\
\hline \multicolumn{2}{|r|}{ CAPABILITIES IN PRODUCT DISTRIBUTION } & 0.03943 \\
\hline HD & Hubungan yang Kuat Dengan Distributor & 0.48838 \\
\hline$M D$ & Mempertahkan Distributor Terbaik & 0.16425 \\
\hline MV & Memberikan Value Terhadap Distributor & 0.10982 \\
\hline TD & $\begin{array}{l}\begin{array}{l}\text { Tingkat Dukungan } \\
\text { Distributor }\end{array} \\
\text { yang }\end{array}$ & 0.23756 \\
\hline \multicolumn{2}{|r|}{ REPUTATIONAL ASSET } & 0.39903 \\
\hline BR & Brand dan Reputasi & 0.75000 \\
\hline KD & Kredibilitas & 0.25000 \\
\hline
\end{tabular}




\subsection{Analisis dan Penentuan Prioritas Alternatif Terpilih dengan Metode Technique for Order Preference by Similarity To an Ideal Solution (TOPSIS) \\ Setelah didapatkan bobot kepentingan untuk masing-masing subkriteria maka} tahapan selanjutnya adalah meranking prioritas untuk alternatif strategi pemasaran terpilih yang dianggap paling sesuai untuk PT. Astra International UD Truck SO Cabang Semarang. Pada penelitian ini, metode yang digunakan untuk merangking prioritas adalah dengan menggunakan metode TOPSIS. Metode ini dipilih karena dengan menggunakan TOPSIS, alternatif yang nantinya terpilih memiliki jarak terdekat dengan solusi ideal, dan jarak terjauh dengan solusi ideal negatif.

Metode ini memiliki prinsip dasar yaitu bahwa alternatif yang terpilih haruslah memiliki jarak terdekat dari solusi ideal dan jarak terjauh dari solusi negatif-ideal [5]. Solusi ideal positif didefiniskan sebagai jumlah dari seluruh nilai terbaik yang dapat dicapai untuk setiap atribut, sedangkan solusi negatif-ideal terdiri dari seluruh nilai terburuk yang dapat dicapai untuk setiap atribut. TOPSIS mempertimbangkan keduanya, jarak terhadap solusi ideal positif dan terhadap solusi ideal negatif dengan mengambil kedekatan relatif terhadap solusi ideal positif. Adapun tahapan dari metode TOPSIS adalah sebagai berikut:

a. Menghitung matriks keputusan yang ternormalisasi setiap elemen $x i j$

$$
r_{i j}=\frac{x_{i j}}{\sqrt{\sum_{i=1}^{m} x_{i j}^{2}}}
$$

b. Membuat matriks keputusan yang ternormalisasi terbobot Dengan bobot $w j=(w 1, w 2, w 3, \ldots, w n)$, dimana wj adalah bobot dari kriteria ke-j dan $\sum_{j=1}^{n} w_{j}=1$ maka normalisasi bobot matriks $\mathrm{V}$ adalah $v_{i j}=w_{j} r_{i j}$

c. Menentukan solusi ideal positif dan solusi ideal negatifSolusi ideal positif dinotasikan dengan $A_{+}$, sedangkan solusi ideal negatif dinotasikan dengan $A_{-}^{-}$, Berikut ini adalah persamaan dari $A+$ dan $A-$ :

$$
\begin{aligned}
& A^{+}\left\{\left(\max v_{i j} \mid j \in J\right),\left(\min v_{i j} l j \in J^{2}\right) i=1,2,3, \ldots, m\right\}=\left[v_{1}^{+}, v_{2}^{+}, v_{2}^{+}, \ldots, v_{n}^{+}\right] \\
& \left.A^{-}\left\{\left(\min v_{i j} \mid j \in J\right),\left(\max v_{i j}\right] j \in J^{7}\right) i=1,2,3, \ldots, m\right\}=\left\{v_{1}^{-}, v_{2}^{-}, v_{a}^{-}, \ldots, v_{n}^{-}\right]
\end{aligned}
$$

d. Menghitung separasi

1. $\mathrm{S}^{+}$adalah jarak alternatif dari solusi ideal positif didefinisikan sebagai,

$$
S_{1}^{+}=\sqrt{\sum_{j=1}^{n}\left(v_{i j}-v_{j}^{*}\right)^{2}} \text { Dengan } \mathrm{I}=1,2,3, \ldots, \mathrm{m}
$$

2. $S^{-}$adalah jarak alternatif dari solusi ideal negatif didefinisikan

$$
\text { sebagai, } S_{1}^{-}=\sqrt{\sum_{j=1}^{n}\left(v_{i j}-v_{j}\right)^{2} \text { Dengan } \mathrm{I}=1,2,3, \ldots, \mathrm{m}}
$$

e. Menghitung kedekatan relative terhadap solusi ideal positif

Kedekatan relative dari setiap alternatif terhadap solusi ideal positif dapat dihitung dengan menggunakan persamaan berikut

$$
c_{i}^{+}=\frac{s_{i}^{-}}{\left(s_{i}^{-}+s_{i}^{+}\right)}, 0 \leq C_{i}^{+} \leq 1 \text { : }
$$

f. Merangking alternatif

Alternatif diurutkan dari nilai $\mathrm{C}_{+} \quad$ terbesar ke nilai yang terkecil. Alternatif denagn nilai $\mathrm{C}_{+}$ terbesar merupakan solusi yang terbaik.

Tahapan pertama yang dilakukan metode TOPSIS adalah disebarkannya kuesioner judgement. Kuesioner ini bertujuan untuk mengetahui kecocokan pilihan alternatif yang akan direkomendasikan dengan subkriteria atau sumber daya pemasaran yang dimiliki oleh PT. Astra International UD Truck SO Cabang Semarang. Kuesioner ini memiliki 5 skala, yaitu sangat buruk, buruk, cukup, baik dan sangat baik. Sebagai contoh, untuk subkriteria kondisi finansial, responden satu memberikan nilai masing- masing 2, 3, dan 4 untuk berturut-turut alternatif cost leadership strategy, differentiation strategy, Kondisi finansial merupakan kemampuan perusahaan untuk mengatur keuangannya dalam mendukung pemasaran produk PT. Astra International UD Truck SO Cabang Semarang. Dalam keadaan kondisi finansial ini, strategi cost leadership, dimana perusahaan bertujuan untuk menjadi produsen dengan harga yang lebih rendah dari pesaing tanpa mengurangi keuntungan dianggap tidak sesuai bagi perusahaan. Karena dalam 
mengurangi harga jual produk, akan sulit bagi perusahaan mempertahankan keuntungan yang ditargetkan. Cost leadership strategy membutuhkan penggunaan fasilitas yang efesien, pembiayaan dan kontrol biaya yang ketat. Namun hal ini akan membutuhkan investasi modal yang cukup tinggi untuk memiliki peralatan agar dapat menghasilkan efesiensi penggunaan peralatan. Kemudian nilai kesesuaian alternatif diferentation strategy adalah 3 (cukup). Berarti kemampuan perusahaan dalam kondisi finansial dianggap cukup jika alternatif strategi differensiasi diterapkan, dan nilai kesesuaian alternatif strategi segmentasi adalah 3 untuk kondisi finansial. Maksudnya adalah, dengan kondisi finansial saat ini, jika alternatif segmentasi dianggap baik bagi perusahaan.

Tahapan selanjutnya adalah menyatukan hasil kuesioner judgment dari ketiga responden dengan menghitung rata-rata untuk setiap subkriteria (Tabel 5). Hasil rekapitulasi matriks keputusan dapat dilihat pada Tabel 6. Setelah itu, tahapan berikutnya adalah mengkallkulasikan matriks keputusan normalisasi dengan menggunakan rumus (1) dan hasil rekapitulasi matriks keputusan normalisasi dapat dilihat pada Tabel 7. Kemudian, matriks keputusan ini dinormalisasikan dengan cara mengkalikan nilai pada matriks keputusan nornalisasi terhadap bobot masing-masing subkriteria Cara perhitungan yang sama dilakukan untuk keseluruhan subkriteria dan alternatif, hasil rekapitulasi matriks keputusan normalisasi terbobot dapat dilihat pada Tabel 8.

. Tabel 5 Rekapitulasi Nilai Rata-rata Bobot Normalized by All Element

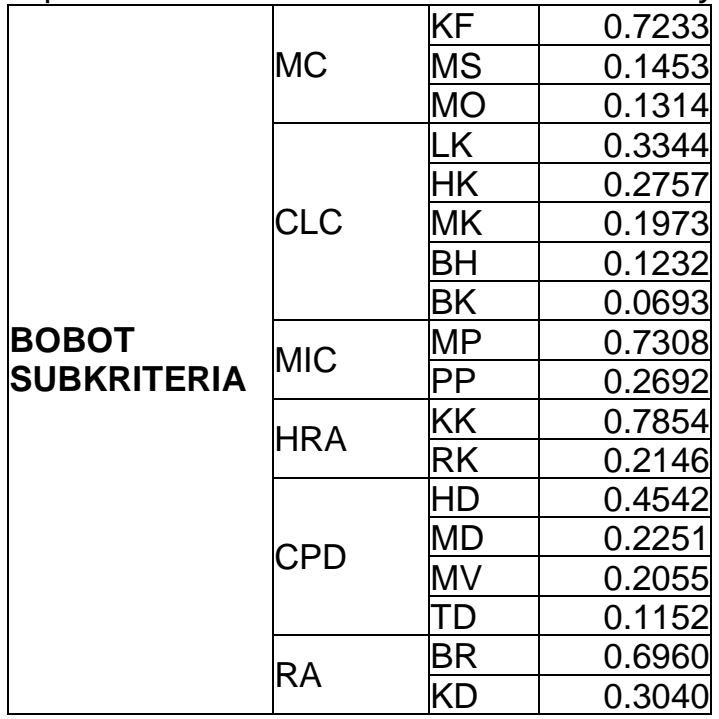

Setelah didapatkan matriks keputusan normalisasi terbobot, tahapan selanjutnya adalah mencari solusi ideal positif dan negatif untuk masing-masing subkriteria terhadap pilihan alternatif strategi yang ada. Solusi ideal positif didefinisikan sebagai jumlah dari seluruh nilai terbaik yang dapat dicapai untuk setiap subkriteria. Untuk setiap subkriteria, dipilih nilai terbesar dan terkecil yang kemudian akan menjadi solusi ideal positif dan negatif untuk masingmasing subkriteria. Setelah itu, dilakukan perhitungan dengan menggunakan rumus (3) untuk menghitung jarak terhadap solusi ideal positif dan rumus (4) untuk menghitung jarak terhadap solusi ideal negatif untuk masing-masing alternatif strategi pemasaran berdasarkan Porter. nilai kedekatan untuk masing-masing alternatif adalah 0 untuk alternatif Cost Leadership Strategy, 0,7688 untuk alternatif Differentiation Strategy, dan 0,9282 untuk alternatif Segmentation Strategy. Sehingga dapat disimpulkan bahwa yang memilihi nilai $v$ dengan jarak kedekatan setiap alternatif terhadap solusi ideal adalah V3 yaitu alternatif Segmentation Strategy.

Untuk differentiation strategy dan 0,1001 untuk alternatif segmentation strategy. Sedangkan untuk jarak antara nilai terbobot dengan solusi ideal negatif untuk masing-masing alternatif strategi adalah 0,0652 untuk cost leadership strategy, 0,0778 untuk differentiation strategy, dan 0,1110 untuk segmentation strategy. Dari hasil ini, maka dapat disimpulkan bahwa alternatif strategi pemasaran terpilih untuk PT. Astra International UD Truck SO Cabang Semarang dengan mempertimbangkan sumber daya pemasaran perusahaan adalah segmentation strategy. 
Tabel 6 Matriks Keputusan

\begin{tabular}{|c|c|c|c|c|c|c|c|c|c|c|c|c|c|c|c|c|c|c|c|}
\hline $\begin{array}{c}\text { Alternatif Strategi } \\
\text { Pemasaran }\end{array}$ & \multirow{2}{*}{\begin{tabular}{|c|} 
Subkriteria \\
Cost Leadership \\
Strategy \\
\end{tabular}} & \multirow{2}{*}{$\begin{array}{ll}\mathrm{C} 1 \\
2.33\end{array}$} & \multirow{2}{*}{$\begin{array}{l}\mathrm{C} 2 \\
2.67\end{array}$} & \multirow{2}{*}{$\frac{\mathrm{C} 3}{3.00}$} & \multirow{2}{*}{$\frac{\mathrm{C} 4}{3.00}$} & \multirow{2}{*}{$\frac{\mathrm{C} 5}{3.33}$} & \multirow{2}{*}{$\begin{array}{ll}\mathrm{C} 6 \\
3.33\end{array}$} & \multirow{2}{*}{$\frac{\mathrm{C} 7}{3.33}$} & \multirow{2}{*}{$\frac{\mathrm{C} 8}{3.33}$} & \multirow{2}{*}{$\frac{\mathrm{C} 9}{2.67}$} & \multirow{2}{*}{$\frac{\mathrm{C} 10}{3.00}$} & \multirow{2}{*}{$\frac{\mathrm{C} 11}{2.33}$} & \multirow{2}{*}{$\frac{\mathrm{C} 12}{2.33}$} & \multirow{2}{*}{$\frac{\mathrm{C} 13}{2.33}$} & \multirow{2}{*}{$\frac{\mathrm{C} 14}{3.00}$} & \multirow{2}{*}{$\frac{\mathrm{C} 15}{2.33}$} & \multirow{2}{*}{$\frac{\mathrm{C} 16}{3.33}$} & \multirow{2}{*}{$\begin{array}{l}\mathrm{C} 17 \\
3.33\end{array}$} & \multirow{2}{*}{\begin{tabular}{|l}
$\mathrm{C} 18$ \\
2.67
\end{tabular}} \\
\hline \multirow{3}{*}{$\begin{array}{l}\text { Alternatif Strategi } \\
\text { Pemasaran }\end{array}$} & & & & & & & & & & & & & & & & & & & \\
\hline & Diferensiasi & 3.33 & 3. & 3.67 & 4.00 & 3.33 & 4.00 & 3.67 & 3.33 & 4.00 & 3.67 & 4.00 & 3.33 & 3.00 & 3.33 & 3.00 & 3.33 & 4.00 & 3.67 \\
\hline & Segmentasi & 3.33 & 4.33 & 3.67 & 4.33 & 4.67 & 4.00 & 3.67 & 3.33 & 3.33 & 3.33 & 4.33 & 4.33 & 3.33 & 3.67 & 4.00 & 3.33 & 4.00 & 4.00 \\
\hline
\end{tabular}

Tabel 7 Matriks Keputusan Normalized

\begin{tabular}{|c|c|c|c|c|c|c|c|c|c|c|c|c|c|c|c|c|c|c|c|}
\hline & Subkriteria & $\mathrm{C} 1$ & $\mathrm{C} 2$ & $\mathrm{C} 3$ & C4 & $\mathrm{C} 5$ & C6 & $\mathrm{C} 7$ & $\mathrm{C} 8$ & C9 & $\mathrm{C} 10$ & $\overline{\mathrm{C} 11}$ & $\mathrm{C} 12$ & $\mathrm{C} 13$ & C14 & $\mathrm{C} 15$ & $\mathrm{C} 16$ & $\mathrm{C} 17$ & $\mathrm{C} 18$ \\
\hline \multirow{3}{*}{$\begin{array}{c}\text { Alternatif Strategi } \\
\text { Pemasaran }\end{array}$} & $\begin{array}{c}\text { Cost Leadership } \\
\text { Strategy }\end{array}$ & 0.4436 & 0.4384 & 0.5008 & 0.4534 & 0.5025 & 0.5077 & 0.5407 & 0.5774 & 0.4558 & 0.5179 & 0.3679 & 0.3925 & 0.4616 & 0.5179 & 0.4229 & 0.5774 & 0.5077 & 0.4411 \\
\hline & Diferensiasi & 0.6337 & 0.5480 & 0.6121 & 0.6046 & 0.5025 & 0.6092 & 0.5948 & 0.5774 & 0.6838 & 0.6330 & 0.6307 & 0.5608 & 0.5934 & 0.5754 & 0.5437 & 0.5774 & 0.6092 & 0.6064 \\
\hline & Segmentasi & 0.6337 & 0.7124 & 0.6121 & 0.6549 & 0.7035 & 0.6092 & 0.5948 & 0.5774 & 0.5698 & 0.5754 & 0.6833 & 0.7290 & 0.6594 & 0.6330 & 0.7249 & 0.5774 & 0.6092 & 0.6616 \\
\hline \multicolumn{20}{|c|}{ Tabel 8 Matriks Keputusan Weighted Normalized } \\
\hline & & $\mathrm{Cl}$ & $\mathrm{C} 2$ & $\mathrm{C3}$ & C4 & C5 & C6 & C7 & $\mathrm{CB}$ & $\mathrm{Cg}$ & $\mathrm{C} 10$ & $\mathrm{C} 11$ & $\mathrm{Cl} 2$ & $\mathrm{C13}$ & $\mathrm{Cl4}$ & $\mathrm{C} 15$ & C16 & $\mathrm{Cl} 17$ & $\mathrm{C} 18$ \\
\hline \multirow{3}{*}{$\begin{array}{l}\text { Altemntif Strategi } \\
\text { Pemasaran }\end{array}$} & $\begin{array}{c}\text { Cost Leadership } \\
\text { Strategy }\end{array}$ & 0.3208 & 0.0637 & 658. & 0.1516 & 0.1385 & 0.1002 & 0.0666 & 0.0400 & 0.3331 & 0.1394 & 02889 & 0.0842 & 0.2096 & 0.1166 & 0.0869 & 0.0665 & 0.3533 & 0.1 \\
\hline & Diferersisai & 0,4584 & 0.0796 & 0.0804 & 0.2022 & 0.1385 & 0.1202 & 0.0733 & 0.0400 & 0,4997 & 0.1704 & 0.4953 & 0.1204 & 0.2695 & 0.1295 & 0.1117 & 0.0665 & 0.4240 & 0.18 \\
\hline & Segmentasi & 0.4584 & 0.1035 & 0.0804 & 0.2190 & 0.1940 & 0.1202 & 0.0733 & 0.0400 & 0.4164 & 0.1549 & 0.5366 & 0.1565 & 0.2995 & 0.1425 & 0.1490 & 0.0665 & 0.4240 & 0.2011 \\
\hline
\end{tabular}

\section{Kesimpulan}

Terdapat dua jenis hubungan, yaitu inner dependence dan outer dependence. Kriteria managerial capabilities (MC), customer linking capabilities (CLC), market innovation capabilities (MIC), human resource assets (HRA), capabilities in Product Distribution (CPD), dan reputational assets (RA), masing- masing kriteria memiliki inner dependence dan outer dependence. Setelah melakukan perhitugan dengan metode ANP didapatkan bobot untuk masing-masing kriteria dan subkriteria. Bobot tertinggi untuk kriteria yaitu Managerial Capabilities dengan bobot 0.2601 , dan bobot tertinggi untuk subkriteria yaitu Tingkat Kepuasan Kinerja Karyawan dengan bobot 0.7854 . Berdasarkan penghitungan TOPSIS didapatkan prioritas alternatif strategi pemasaran bagi PT. Astra International UD Truck SO Cabang Semarang. Alternatif terpilih adalah Segmentation Strategy. Rekomendasi yang diberikan bagi PT. Astra International UD Truck SO Cabang Semarang yaitu lebih memfokuskan segmen pada kelas small medium enterprise, medium enterprise, dan high enterprise. Dan dengan memprioritaskan penjualan light duty truck, light medium duty truck, medium duty truck, dan heavy duty truck. Dengan demikian, perusahaan dapat lebih maksimal dalam menggunakan sumber daya pemasaran yang dimiliki berdasarkan hasil bobot subkriteria.

\section{Referensi}

[1]. Christensen, H. K., 2010. UDefining Customer Value As The Driver Of Competitive Advantage. Strategy \& Leadership,38: 20-25.

[2]. Mohaghar, A. et al. (2012). A Combined VIKOR-Fuzzy AHP Approach to Marketing strategy Selection. 1 (3). ISSN 2157-6068.

[3]. Hooley, G.J., Greenley, G.E., Cadogan, J.W., Fahy, J., 2005. The Performance Impact Of Marketing Resource. Journal Business Research 58: 18-27.

[4]. Olivia, Grace. 2013. Pemilihan Strategi Pemasaran Pada PT. Nyonya Meneer Dengan Menggunakan Metode Analytical Network Process (ANP) dan Technique for order preference by Similarity to an ideal solution (TOPSIS). Universitas Diponegoro: Semarang.

[5]. Opricovic, S., Tzeng, G.H., 2002. Multicriteria planning of post-earthquake sustainable reconstruction. The Journal of Computer-Aided Civil and Infrastructure Engineering 17 (3), 211-220. 